\title{
Autoantibody to nerve tissue in a patient with a peripheral neuropathy and an IgG paraprotein
}

\author{
HF SEWEll, JB MATTHEWS, * ELAine gooCh, P Millac, $\dagger$ A WilloX, \\ MA STERN, F WALKER \\ From the Immunopathology Laboratory, Leicester Royal Infirmary and Department of Pathology \\ University of Leicester, the *Immunology Laboratory, Department of Oral Pathology, University of \\ Birmingham, and the †Department of Neurology, Leicester Royal Infirmary, Leicester
}

SUMMARY The antibody activity of a benign $\operatorname{IgG} \lambda$ paraprotein to nerve tissue in a case of peripheral neuropathy has been investigated using immunohistochemical methods on trypsin-treated, formalin-fixed, paraffin-embedded tissue. $\operatorname{IgG} \lambda$ was found in the sural nerve biopsy of the patient. Specific binding of the purified $\operatorname{IgG} \lambda$ paraprotein and its isolated $F\left(a^{\prime}\right)_{2}$ fragment to homologous nerve and brain tissue was demonstrated. Similar activity was not demonstrable on fresh frozen cryostat sections. The results suggest that tests for autoantibodies to nerve tissue in neuropathological disorders should not be confined to fresh frozen tissue substrates.

Peripheral neuropathies have been described associated with multiple myeloma, ${ }^{1}$ Waldenström's macroglobulinaemia, 23 cryoglobulinaemia, 4 benign paraproteinaemia ${ }^{56}$ and with primary and secondary amyloidosis. ${ }^{7}$ Autologous binding to nerve in dysproteinaemic neuropathies was originally described in patients with IgG and IgA myeloma, ${ }^{8}$ macroglobulinaemia ${ }^{3}$ and IgG and IgM benign paraproteinaemia. ${ }^{6}$ Homologous activity of paraproteins is confined to a report in which an IgG myeloma protein was shown to bind to alcoholdamaged peripheral nerve. ${ }^{8}$ Attempts to detect homologous binding activity of benign paraproteins have been unsuccessful. ${ }^{9}$

In the present study we report immunopathological studies on a patient with an IgG paraprotein and an associated peripheral neuropathy which demonstrate that the paraprotein has autologous and homologous anti-nerve activity.

\section{Case report}

A 57-year-old tool fitter was admitted to the Leicester Royal Infirmary in April 1979. Four years before admission he had developed a hoarse voice and was found to have a left vocal cord paresis; chest $x$-ray and biopsy of the cord were normal. Two and a

Accepted for publication 9 March 1981 half years before admission he had developed numbness below both knees, initially in the left leg. He complained that his feet felt cold and dead. At that time serum analysis revealed an IgG paraprotein band at a concentration of $8 \mathrm{mg} / \mathrm{ml}$. Two months later he noticed tingling in the fingers and felt his grip was not as good as it had been. Both legs had become weak one year before admission. On admission he was unable to climb stairs and walked with the aid of a Zimmer frame. He had poor grip in both hands though most marked in his left, and had great difficulty lifting objects above his head. His legs felt numb below both knees. These symptoms had remained relatively static for about 10 months. On examination he was hoarse and had a waddling broad-based gait. Muscle weakness and wasting was most obvious in his proximal muscle groups, though also severely affecting his hands. There was loss of pin pricksensation in the tips of his fingers of his left hand. Hehad absent vibration sensation below both iliac crests. Pin prick sensation was diminished from the knee downward on the left and midcalf level downwards on the right.

Routine investigations including full blood count, plasma viscosity, liver function test, urea, electrolytes, blood sugar, calcium, phosphate and thyroid function tests were normal, as was a chest $x$-ray and skeletal survey. Electrophysiological studies confirmed a sensory-motor neuropathy. 


\section{Material and methods}

Blood, cerebrospinal fluid (CSF), bone marrow and sural nerve were obtained from the patient and control peripheral nerve and brain tissue, without histopathological evidence of abnormality, from routine necropsies.

Immune complexes were assayed by the platelet aggregation test described by Penttinen et al. ${ }^{10}$ Fresh non-heated serum samples were assayed together with appropriate positive (heat-aggregated IgG) and negative controls.

A general autoantibody screen for mitochondrial, nuclear, smooth muscle, rheumatoid factor, and thyroid antibodies was performed.

Zone electrophoresis was performed in $1.5 \%$ agarose. Immunoelectrophoresis and immunoglobulin quantification by single radial immunodiffusion was performed by standard procedures. ${ }^{11} 12$

IgG was purified from the patients serum by ionexchange chromatography on DEAE-cellulose (Whatman DE 52) and the $F\left(a b^{\prime}\right)_{2}$ fragment isolated after pepsin digestion and chromatography on Sephadex (G-150) (Pharmacia). Purity of the IgG and $F\left(a b^{\prime}\right)_{2}$ preparations was determined by immunoelectrophoresis against antisera to whole human serum, Fab $\gamma$ and $\mathrm{Fc} \gamma$ fragments.

Immunoperoxidase staining by the unlabelled antibody peroxidase-antiperoxidase (PAP) method was performed on formalin-fixed, paraffin-embedded tissues, after trypsinisation, ${ }^{13}$ as previously described. ${ }^{14}$ Controls included omission of the primary and secondary layers, replacement of primary antiserum with normal rabbit serum plus specific inhibition by the appropriate purified human immunoglobulin or kappa and lambda Bence-Jones protein. Reagents were obtained from Dakopatts AS, Denmark. Parallel direct immunofluorescence assays on the same tissue were performed with appropriate controls. Fluorescence-conjugated antisera were purchased from Behringwerke AG.

Specific binding of the patient's IgG $\gamma$ paraprotein to homologous tissues (necropsy peripheral nerve and brain), was performed on formalin-fixed paraffin-embedded trypsin-treated sections. Sections were overlayed $(30 \mathrm{~min})$ with dilutions of the patient's serum, purified IgG, $F\left(a b^{\prime}\right)_{2}$ fragment of the IgG, a control serum pool (200 individuals), six individual control sera, two sera from patients with peripheral neuropathy associated with diabetes mellitus, and IgG $\kappa$ and IgG $\lambda$ myeloma sera obtained from patients without symptoms of neuropathy. Immunoglobulin bound to the nerve tissue was then visualised using immunoperoxidase or immunofluorescence methods.

Specific binding of the IgG $\lambda$ paraprotein was also tested using indirect immunofluorescence on un-
Quantification of serum proteins

\begin{tabular}{lll}
\hline & WN serum $(\mathrm{g} / \mathrm{l})$ & Normal range $(\mathrm{g} / \mathrm{l})$ \\
\hline Total protein & 57 & $60-80$ \\
Albumin & 32 & $36-52$ \\
Immunoglobulins: & & \\
IgG & $7 \cdot 70$ & $6-16$ \\
IgM & $0 \cdot 25$ & $0 \cdot 25-1 \cdot 60$ \\
IgA & $0 \cdot 25$ & $0 \cdot 90-5 \cdot 0$ \\
\hline
\end{tabular}

fixed cryostat sections of a control peripheral nerve biopsy. Briefly sections $(5 \mu \mathrm{m})$ were washed in phosphate-buffered saline (PBS pH 7.4: $2 \times 5 \mathrm{~min}$ ) and overlayed with dilutions of the patient's purified $\operatorname{IgG} \lambda$, serum and control sera for $30 \mathrm{~min}$ at room temperature. After washing in PBS $(3 \times 5 \mathrm{~min})$ sections were overlayed with fluorescein-conjugated antisera $(30 \mathrm{~min})$, washed in PBS $(3 \times 5 \mathrm{~min})$, mounted in $30 \%$ glycerol and viewed using a Leitz Orthoplan microscope equipped with an XBO $150 \mathrm{~W}$ lamp.

\section{Results}

ANALYSIS OF SERUM, CSF AND BONE MARROW The Table shows a depression of general and specific proteins in the patients' serum. Zone electrophoresis and immunoelectrophoresis indicated an $\operatorname{IgG} \lambda$ paraprotein band which was estimated at $6.5 \mathrm{mg} / \mathrm{ml} \Omega$ Analysis of the CSF revealed a raised total protein concentration $(1 \cdot 17 \mathrm{~g} / \mathrm{l})$, the IgG content of which was in the normal range-that is, IgG of CSF $=2 \%$ of the total protein. The platelet aggregation test revealed immune complexes in serum; none was found in the CSF. A general autoantibody screen for antinuclear factor, rheumatoid factor, thyroid, antimitochondrial and anti-smooth muscle antibodies was negative.

Bone marrow smears examined by light microscopy revealed an atypical marrow, but not one consistent with myeloma. Immunofluorescent studies on the marrow aspirate also gave no evidence consistent with myeloma. The patient's urine was negative for Bence-Jones and other immunoglobulin elements (urine concentrated $\times 50$ ).

\section{HISTOLOGY OF SURAL NERVE BIOPSY}

The sural nerve biopsy showed a slight degree of segmental demyelination and borderline Schwann cell proliferation. There was no cellular infiltration and no evidence of amyloid.

IMMUNOHISTOCHEMICAL STAINING OF SURAL NER VE BIOPSY

Immunoperoxidase and immunofluorescence revealed the presence of IgG $\lambda$ bound to the patient's sural nerve (Figure). Positive staining for IgG was related to the myelin sheath of the nerve fibres. 


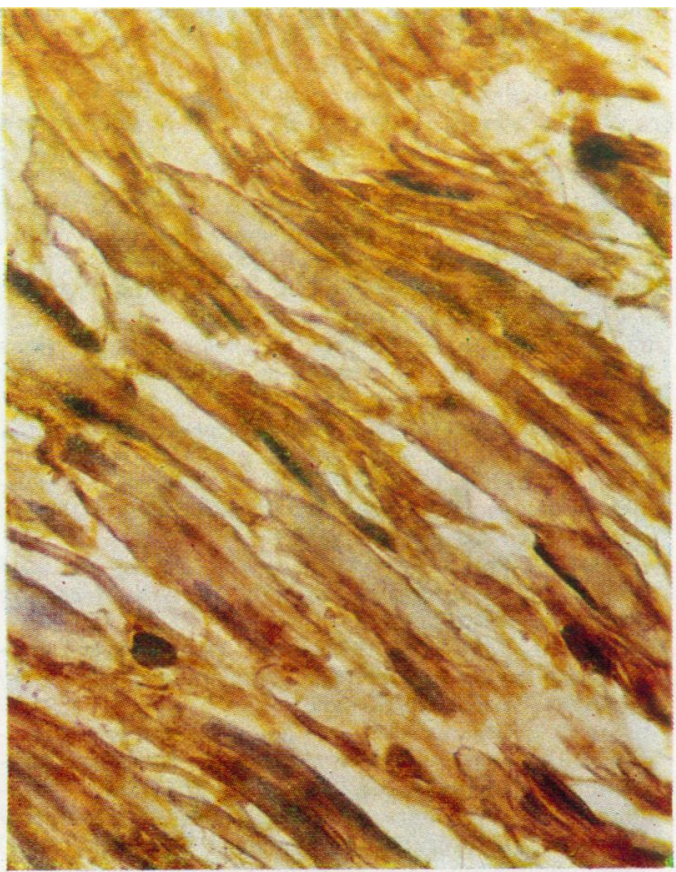

(a)

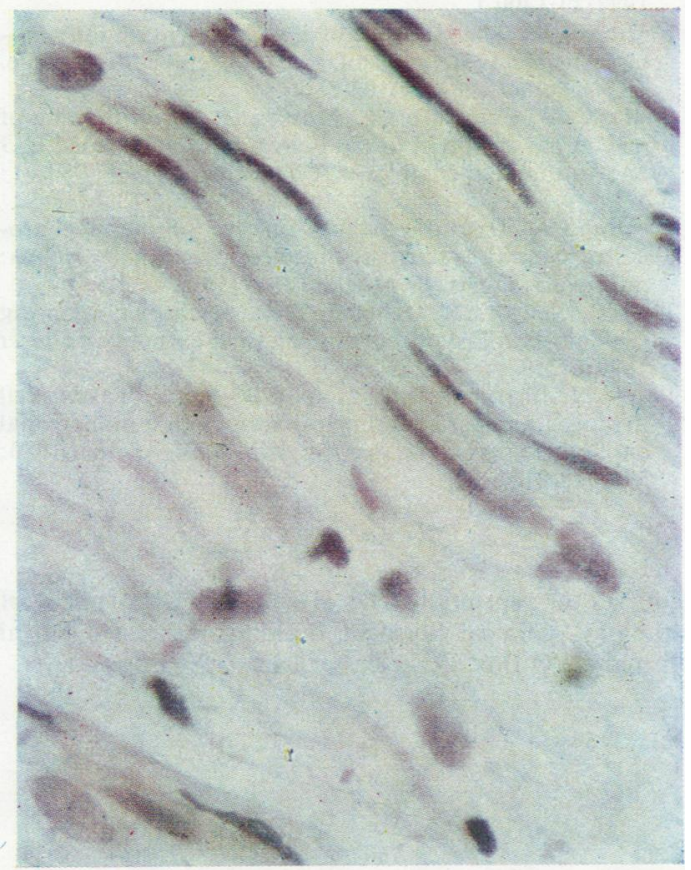

(b)

Demonstration of paraprotein bound to the sural nerve biopsy of patient, by the immunoperoxidase technique. Staining for (a) lambda $(\lambda)$ chains (b) kappa ( $\kappa)$ chains.
There was no staining associated with the interfibre connective tissue, nor with the nerve fibre proper. Control nerve and brain tissues were negative for all immunoglobulin classes.

SPECIFIC BINDING OF IGG PARAPROTEIN TO HOMOLOGOUS PERIPHERAL NERVEAND BRAIN TISSUES

Serum, purified IgG and $F\left(a b^{\prime}\right)_{2}$ fragments of the patient were tested with various control sera for binding to necropsy peripheral nerve and brain. The formalin-fixed, paraffin-embedded, trypsinised sections were treated for $30 \mathrm{~min}$ with dilutions of sera $(1 / 20-1 / 5000)$ or IgG and $F\left(\mathrm{ab}^{\prime}\right)_{2}(1 \cdot 0-0.002$ $\mathrm{mg} / \mathrm{ml}$ ) then washed and tissue bound immunoglobulin visualised by PAP or immunofluorescent staining. The patient's serum, IgG and $F\left(a b^{\prime}\right)_{2}$ fragment gave positive binding (for $\operatorname{IgG} \lambda$ ) to peripheral nerve and brain at dilutions of up to $1 / 5000$ for serum and at $0.002 \mathrm{mg} / \mathrm{ml}$ for the purified IgG and $F\left(a^{\prime}\right)_{2}$ preparations. The staining pattern for homologous peripheral nerve was similar in distribution to that obtained in the autologous biopsy. The brain sections showed predominant staining related to white matter. Control sera gave no detectable binding of immunoglobulin to tissue substrates.

In contrast to these results when homologous binding was performed on unfixed cryostat sections, using similar dilutions of reagents, no binding could be demonstrated.

\section{Discussion}

A patient is described with a peripheral neuropathy associated with an IgG paraprotein first demonstrated two and a half years before these studies. There is no evidence of myeloma or a collagen disorder, nor any evidence of a primary tumour and therefore it may be regarded as a "benign paraprotein." This protein, however, has anti-nerve tissue binding specificity as demonstrated by autologous and homologous studies using peripheral and central nerve tissues. The specificity of the binding is confirmed by the negative results obtained with control sera and the possibility that the reaction is a non-specific Fc mediated reaction ${ }^{15}$ is unlikely as the binding was obtained using the pepsin-derived $F\left(a b^{\prime}\right)_{2}$ fragment. The occurrence of antibody to neural tissue together with peripheral neuropathy raises the question of cause or effect; this is well reviewed and discussed in the British Medical Bulletin. ${ }^{16}$ The precise nature of the antigen to which the antibody binding is occurring is under investigation but preliminary results suggest a myelin-related product, possibly myelin basic protein.

Three similar clinical cases have been described" 
but analysis of homologous binding of the paraproteins on frozen sections proved negative and autologous studies were not performed. If these cases were similar to the present case report the discordant results may be a reflection of differences in technique. Our homologous (and autologous) binding assays were performed on formalin-fixed paraffin-embedded tissues using a trypsinisation procedure. This method may favour display in the tissue of the relevant antigenic epitopes (or altered tissue antigens to which the antibody has specificity) that are minimally expressed, or absent, in fresh frozen tissues as we also obtained negative results on frozen sections. Indeed it is known that immunohistochemical staining of myelin basic protein is optimal when frozen sections of brain, cord or peripheral nerve are treated with alcohol to remove myelin lipids (Dr S Leibowitz, personal communication, 1981). Alternatively negative results on frozen sections may be attributable to elution of the antigen from the tissue in its unfixed state. Whatever the reason for the difference in results, the technique of using formalin-fixed paraffin-embedded tissues, with trypsinisation may be of significance in immunological studies of other neuropathological disorders, both retrospective and prospective.

The documented presence of an immunoglobulin with specific autologous anti-nerve activity raises intriguing possibilities with regard to patient management. A recent study ${ }^{17}$ has reported favourable results on treating relapsing Guillain-Barré syndrome by plasma exchange. Such clinical studies and immunological investigations may suggest that plasma exchange has an important role in the management of certain neuropathies.

Recently it has been demonstrated that an IgM $\kappa$ monoclonal protein in the serum of a patient with a chronic demyelinative neuropathy, had antibody activity directed towards some component or components of isolated normal human peripheral nerve myelin. ${ }^{18}$

We are indebted to Mrs Geraldine Holmes for preparing the manuscript.

\section{References}

1 Victor M, Banker B, Adams RD. The neuropathy of multiple myelomas. $J$ Neurol Neurosurg Psychiatry $1958 ; 21: 73-88$.

2 Dayan AD, Lewis PD. Demyelinating neuropathy in macroglobulinaemia. Neurology 1966;16:1141-4.

${ }^{3}$ Propp RP, Means E, Diekel R, et al. Waldenström's macroglobulinaemia and neuropathy. Neurology 1975; $25: 930-88$.

4 Cream JJ, Hern JEC, Hughes RAC, et al. Mixed or immune complex cryoglobulinaemia and neuropathy. $\frac{\overline{\bar{n}}}{\bar{T}}$ J Neurol Neurosurg Psychiatry 1974;37:82-7.

s Hobbs JR, Carter PM, Cooke KB, et al. IgM paraprotein. J Clin Pathol 1976;28, suppl 6:54-64.

- Chazot G, Berger G, Carrier H, et al. Manifestations ๗ֶ) neurologique des gammapathies monoclonales. $\operatorname{Rev} \vec{\circ}$ Neurol (Paris) 1976;132:195-212.

${ }^{7}$ Benson MD, Brands KD, Cohen AS, et al. Neuropathy, $\overrightarrow{\vec{\omega}}$ $M$ components and amyloid. Lancet $1975 ; \mathrm{i}: 10-12$.

${ }^{8}$ Chazot G, Berger G, Bady B, et al. Neuropathie peripherisque au cours des dysglobulinemies malignes. $\frac{7}{0}$

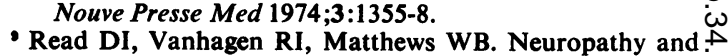
benign IgG paraproteinaemia. $J$ Neurol Neurosurg $\vec{O}$ Psychiatry 1978;41:215-9.

10 Penttinen K, Myllylä G, Mäkelä $O$, et al. Antigen anti- $\vec{\overrightarrow{ }}$ body complexes and platelet aggregation. Acta Pathol Microbiol Scand 1969;77:269.

11 Grabar P, Williams CA. Methods of immunoelectrophoretique d'analyse de malanges de substances anti- $\overrightarrow{-}$ geniques. Biochim Biophys Acta 1953;10:193-4.

12 Mancini G, Carbonara AO, Heremans JF. Immuno- $\frac{}{+}$ chemical quantification of antigens by single radialo immunodiffusion. Immunochemistry 1965;2:235-41.

${ }^{13}$ Curran RC, Gregory J. The unmasking of antigens in $\vec{c}$ paraffin sections of tissue by trypsin. Experieng $a_{\infty}$ 1977;33:1400-1.

14 Matthews JB. The influence of clearing agent on immunehistochemical staining of paraffin embedded tiss $J$ Clin Pathol 1981 ;34:103-5.

15 Sindic CJM, Cambiaso CL, Masson PL, et al. Binding of myelin basic protein to the $\mathrm{Fc}$ region of aggregated IgG and to immune complexes. Clin Exp Immunol 1980;41: 1-7.

${ }^{16}$ Caspray EA. Humoral factors involved in immune pro- $\overline{\bar{O}}$ cesses in multiple sclerosis and allergic encephalomyelitis: multiple sclerosis. Br MedBull 1977;33:50-3.

17 Levy R, Newkirk R, Ochoa J. Treating chronic relapsing Guillain-Barré syndrome by plasma exchange. Lancet 1979 ;ii:259.

${ }^{18}$ Latov N, Sherman WH, Nemni R, et al. Plasma cello dyscrasia and peripheral neuropathy with a monoclona! antibody to peripheral nerve myelin. N Engl J Med 1980 $303: 618-21$.

Requests for reprints to: Dr HF Sewell, Department of Pathology, Clinical Sciences Building, Leicester Royal글 Infirmary, PO Box 65, Leicester LE2 7LX, England. 